\title{
Knowledge, Attitude and Practice with Regard to Obstructive Sleep Apnoea - A Survey among Dental Clinicians
}

\author{
Lakshmi Ramesh ${ }^{1}$, Nirupama Rajegowda ${ }^{2}$, Pooja Rai ${ }^{3}$ \\ 1,2 Department of Prosthodontics and Crown and Bridge, NITTE (Deemed to Be University), AB Shetty \\ Memorial Institute of Dental Sciences, Mangalore, Karnataka, India. ${ }^{3}$ Department of Global \\ Pharmacovigilance, International Strategic Business Unit, Cadila Pharmaceutical Ltd., Ahmedabad, India.
}

\section{ABSTRACT}

\section{BACKGROUND}

Obstructive sleep apnoea (OSA) is a common sleep disorder that often goes undiagnosed. It has been observed that sleep disorders aren't given adequate importance in dental education. This survey was conducted to access the knowledge, attitude and practice of dental clinicians regarding OSA.

\section{METHODS}

A study was carried out using a 33-item questionnaire that assessed the knowledge of OSA; 2 questions regarding the attitude and practice of OSA amongst dental clinicians along with 1 question on the source of information about OSA. The questions related to knowledge covered OSA-related risk factors, symptoms, complications and treatment of OSA. The survey was passed on via social media.

\section{RESULTS}

111 subjects participated in the survey. Participants showed poor knowledge regarding diabetes mellitus as a complication (7.2\%), increased age as a predisposing factor (22.5\%), nocturia as a symptom (15.3\%) and alcohol restriction as a line of treatment (34\%) for OSA. Chi-square test suggests that comparison of knowledge with experience for cardiovascular disease (CVS) disorders as complications and age \& snoring as predisposing factors shows statistical significance for better knowledge of the experience group of 6 - 10 years. Other knowledge scores were statistically insignificant.

\section{CONCLUSIONS}

The descriptive data suggests that the dental clinicians in this study were informed regarding the knowledge associated with sleep apnoea. The knowledge scores when compared with the years of experience showed that there was statistical significance regarding knowledge of cardiovascular disease as a complication of OSA and age over 45 years \& snoring as a predisposing factor for OSA. The chi-square test indicated that the experience group of 6 - 10 years had better knowledge than the other groups. Although there is no statistical significance in comparison with the other knowledge factors when compared to the years of experience, this could be suggestive of lack of awareness of OSA in the dental curriculum as well as lack of resources such as continued dental education and seminars for updating the knowledge on OSA for practicing dentists.

\section{KEY WORDS}

Obstructive Sleep Apnoea, Questionnaire, Knowledge, Awareness, Practice, Attitude, Survey
Corresponding Author: Dr. Lakshmi Ramesh, Assistant Professor, AB Shetty emorial Institute of Dental Sciences, NITTE (Deemed to Be University), Deralakatte - 575018,

Mangalore, Karnataka, India.

E-mail: lakshmiramesh.nambiar@gmail.com

DOI: 10.14260/jemds/2021/93

How to Cite This Article: Ramesh L, Rajegowda N, Rai P. Knowledge, attitude and practice with regard to obstructive sleep apnoea - a survey among dental clinicians. J Evolution Med Dent Sci 2021;10(07):419-424, $10.14260 /$ jemds/2021/93

Submission 15-10-2020,

Peer Review 20-12-2020,

Acceptance 26-12-2020,

Published 15-02-2021.

Copyright (C) 2021 Lakshmi Ramesh et al. This is an open access article distributed under Creative Commons Attribution License [Attribution 4.0 International (CC BY 4.0)] 


\section{BACKGROUND}

Obstructive sleep apnoea (OSA) is a sleep condition characterised by recurrent collapse of the upper airway tract during sleep, which leads to repetitive episodes of desaturations and arousals. 1 The pharyngeal collapse could be either complete which causes apnoea or partial which causes hypopnea. Fluctuations in gas exchange leads to oxygen desaturation, hypercapnia and sleep fragmentation, all of which contribute to further consequences of obstructive sleep apnoea. Features of OSA include snoring, witnessed apnoea, excessive daytime sleepiness, depression, an increased risk of cardiovascular diseases such as hypertension, stroke, metabolic diseases such as diabetes which can result in even death (mortality. ${ }^{1,2}$ ). These symptoms are more likely due to the contributing factors such as obesity, age and sedentary lifestyles. ${ }^{1}$

Sleep and lack of sleep are common human behaviours and experiences. Sleep disorders and excessive sleepiness are caused due to poor sleep hygiene such as poor sleep habits, poor planning of sleep time, voluntary sleep deprivation with chronic ingestion of coffee, tea or antihistamines. Evidence suggests that sleep disorders are relatively common, and sleepiness has an important impact on increased risk for fatigue-related car accidents, errors and other accidents. ${ }^{3}$ Sleep apnoea decreases the quality of life, decreased work productivity and also imposes a health risk to patients. ${ }^{4}$ Although there are various treatment protocols; the treatment for sleep apnoea is often poorly tolerated or treatment only partially alleviate abnormalities. Therefore, there should be an improvement of patient adherence to the existing treatments and there is a need to develop new treatments or combination of treatments. With regard to obesity, there is a probability of a pharyngeal collapse and a likely increase in number of cases of obstructive sleep apnoea. ${ }^{2}$ Despite high prevalence rates of OSA, up to $90 \%$ of the population have been reported to have not received a prior physician diagnosis of sleep apnea. This could suggest that a large number of sleep apnea subjects remain undiagnosed and untreated. This contributes to the enormous public health burden of OSA. ${ }^{1}$

It is important to recognise the obstructive sleep apnea hypopnea syndrome since treatment exist that can reduce the risk of sleep related crashes as well as cardiovascular risks such as hypertension and angina caused by sleep disruption. Dentists play a vital role in diagnosing, advising, referring and treating patients with sleep apnoea due to their ability to examine the oral cavity and upper airway tract. There are no substantial surveys comparing knowledge, attitudes and practice of dental clinicians to related lifestyle behaviours and sleep disorders. It is necessary to recognise the dental practitioners' attitude towards OSA and assess their knowledge of sleep disorders. ${ }^{3}$ The objective of the study is to assess the awareness level among dental clinicians regarding obstructive sleep apnea syndrome during patient-clinician encounters. Sleep apnea is known to be routinely undiagnosed by clinicians. The study was conducted to determine the understanding and knowledge of sleep apnoea and if the practitioner can recognise it when confronted with the predisposing factors, symptoms, complications and its management. The study also accesses the attitude and confidence of the clinician about diagnosing and treating such patients.

\section{METHODS}

A cross-sectional survey study was carried out amongst dental clinicians in and around Mangalore district. The study was conducted with a self-administered questionnaire. A pilot study to check for the validity and reliability of the questionnaires was carried out with a sample population of 10 subjects. Cronbach's alpha value was found to be 0.8419 (good). These subjects were not included in the final sample. The questionnaire was carried out in English and was passed on via social media. The years of clinical experience was recorded, and the knowledge was compared based on the years of experience. Ethical clearance was obtained from the institutional ethical committee of $\mathrm{AB}$ Shetty Memorial Institute of Dental Sciences, Mangalore. The study duration was September 2020 - October 2020 during which data was collected and statistical analysed.

A study was conducted using a 33-item questionnaire that assessed the knowledge of OSA. The knowledge questions consisted of 5 domains: main predisposing factors, symptoms, complications, diagnosis and treatment of OSA. The knowledge assessment questions were carried out in the form of multiple-choice questions with one or more correct answers and each correct answer ticked was allotted 1 point. There were 3 true or false questions with response options consisting of "true", "false," or "do not know." The 'do not know' choice was also included as a third-response to minimise the effect of guessing and is scored as an incorrect response during response rate calculations, while a score of 1 was allotted for the correct choice and the other choice (wrong) was scored 0.5,6 The total score obtainable ranged from 0 to 33 .

Two questions regarding the attitude and practice of OSA amongst dental clinicians along with 1 question on the source of information about OSA. OSA attitude question assessed the confidence of the clinician to be able to diagnose and treat an obstructive sleep apnoea patient. The response to attitude questions was measured on a five-point Likert scale, ranging from 1 to 5 ( 1 = strongly disagree; $2=$ disagree; $3=$ neither agree nor disagree; $4=$ agree; and $5=$ strongly agree). 6 The practice question was based on whether the clinician had been able to screen, diagnose and treat or refer the patient to a specialist. The years of experience of the clinicians was recorded and was categorized as $1-5$ years, $6-10$ years and $\&>10$ years.

\section{Statistical Analysis}

The data was analysed using Statistical Package for the Social Sciences (SPSS) statistical software version 17. Data was analysed using chi-square test to compare the knowledge score and the attitude of the clinician with years of experiences. All statistical tests were performed at $90 \%$ confidence interval. A P-value lesser than 0.05 was considered to be statistically significant.

\section{RESULTS}

A total of 111 dental clinicians answered the questionnaire. The sample size was calculated using the formula $\mathrm{n}=\mathrm{N} / 1+$ $\mathrm{Ne}^{2}$ At a confidence interval of $90 \%$ with an anticipated standard deviation of 3.2 units as described in a similar article, 
with an acceptable margin of error in estimating true population mean of 0.5 we needed a sample of 110.838784 so we rounded off to 111 .

The maximum achievable knowledge score was 33 . The minimum score was 1 and 29 was the maximum score obtained. $99.1 \%$ of them were familiar with the term OSA.

When asked about the source of knowledge, $38.7 \%$ were familiar with OSA during their post graduate course, $27.9 \%$ during their undergraduate course; $19.8 \%$ self-educated themselves through literature and internet and $12.6 \%$ were educated by attending seminars and conferences. Only $0.9 \%$ was completely unaware of the term OSA.

Complications of obstructive sleep apnoea include diabetes mellitus, hypertension, cardiovascular diseases, daytime sleepiness, mood disorders, road traffic accidents and mortality. $7,8,9,1072$ of the participants were aware of the symptoms of excessive day time sleepiness, with only 8 of them were aware of diabetes mellitus as a complication. (Table 1). Contributing factors for OSA were male sex, age over 45 , obesity, anatomy of upper airway tract, ${ }^{2}$ neck circumference of $43 \mathrm{~cm}$ or 17 inches, snoring, hypertension etc. ${ }^{11,12,13} 83$ participants were aware of the anatomy of upper airway tract as a risk factor for obstructive sleep apnoea while only 25 participants identified that age of over 45 years as a risk factor and 22 identified hypertension as a predisposing factor. (Table 2)

$83.8 \%$ of the participants identified snoring as one of the symptoms while only $15.3 \%$ identified nocturia and $27 \%$ identified attention deficit as symptoms of OSA (Table 3). 61 participants recognised a polysomnography test as the gold standard. 80 participants knew about the use of intra oral appliances as treatment option for OSA and 38 participants knew of alcohol reduction as a line of treatment for OSA. (Table 4)

When questioned about the practice for sleep apnoea in a dental set up, $67 \%$ of the dental clinicians claimed that they did not screen for OSA and the cases would have been undiagnosed. Only $3 \%$ of the clinicians were able to diagnose as well as treat the patients with oral appliances. The attitude of the participating clinicians was recorded by their confidence level in diagnosing and treating patients with sleep apnoea. The response for attitude questions was measured on a five-point Likert scale, which ranged from 1 to 5 ( 1 = strongly disagree; $2=$ disagree; $3=$ neither agree nor disagree; $4=$ agree; and $5=$ strongly agree). $36 \%$ of the participants were least confident with the score 1 on the Likert scale and only 2 $\%$ were with the score 5 and highly confident to diagnose and treat patients with OSA. (Table 5)

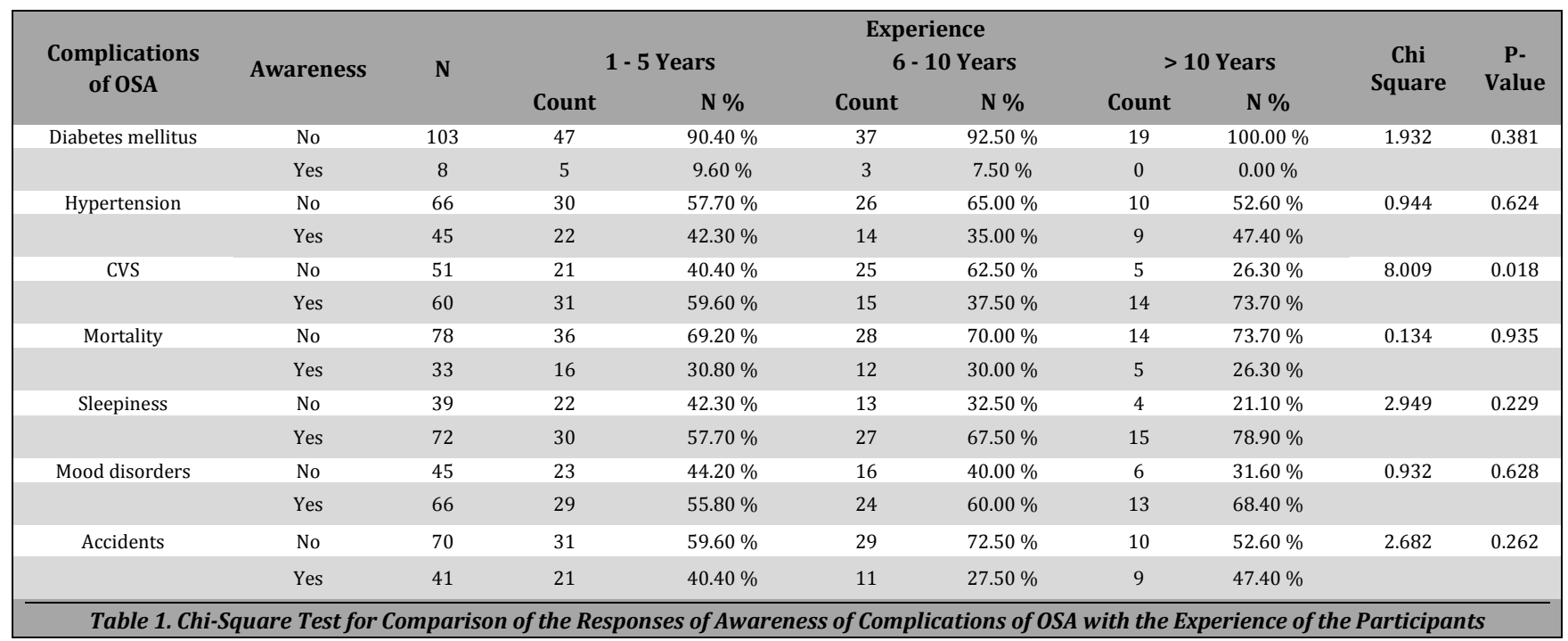

\begin{tabular}{|c|c|c|c|c|c|c|c|c|c|c|}
\hline \multirow{3}{*}{$\begin{array}{l}\text { Predisposing } \\
\text { Factors of OSA }\end{array}$} & \multirow{3}{*}{$\begin{array}{c}\text { Awarene } \\
\text { ss }\end{array}$} & \multirow{3}{*}{$\mathbf{N}$} & \multirow{2}{*}{\multicolumn{4}{|c|}{$\begin{array}{l}\text { Experience } \\
6 \text { - } 10 \text { Years }\end{array}$}} & \multirow{2}{*}{\multicolumn{2}{|c|}{$>10$ Years }} & \multirow{3}{*}{$\begin{array}{l}\text { Chi } \\
\text { Square }\end{array}$} & \multirow{3}{*}{$\begin{array}{c}\text { P- } \\
\text { Value }\end{array}$} \\
\hline & & & & & & & & & & \\
\hline & & & Count & $\underset{\%}{\text { Column }} \mathbf{N}$ & Count & $\begin{array}{c}\text { Column } \\
\%\end{array}$ & Count & $\begin{array}{c}\text { Column } \mathrm{N} \\
\%\end{array}$ & & \\
\hline \multirow[t]{2}{*}{ Male sex } & No & 79 & 35 & $67.30 \%$ & 30 & $75.00 \%$ & 14 & $73.70 \%$ & 0.723 & 0.697 \\
\hline & Yes & 32 & 17 & $32.70 \%$ & 10 & $25.00 \%$ & 5 & $26.30 \%$ & & \\
\hline \multirow[t]{2}{*}{ Age } & No & 86 & 34 & $65.40 \%$ & 37 & $92.50 \%$ & 15 & $78.90 \%$ & 9.554 & 0.008 \\
\hline & Yes & 25 & 18 & $34.60 \%$ & 3 & $7.50 \%$ & 4 & $21.10 \%$ & & \\
\hline \multirow[t]{2}{*}{ Obesity } & No & 33 & 15 & $28.80 \%$ & 14 & $35.00 \%$ & 4 & $21.10 \%$ & 1.236 & 0.539 \\
\hline & Yes & 78 & 37 & $71.20 \%$ & 26 & $65.00 \%$ & 15 & $78.90 \%$ & & \\
\hline \multirow[t]{2}{*}{ Pt who snores } & No & 39 & 15 & $28.80 \%$ & 21 & $52.50 \%$ & 3 & $15.80 \%$ & 9.315 & 0.009 \\
\hline & Yes & 72 & 37 & $71.20 \%$ & 19 & $47.50 \%$ & 16 & $84.20 \%$ & & \\
\hline \multirow[t]{2}{*}{ Neck diameter } & No & 79 & 39 & $75.00 \%$ & 30 & $75.00 \%$ & 10 & $52.60 \%$ & 3.84 & 0.147 \\
\hline & Yes & 32 & 13 & $25.00 \%$ & 10 & $25.00 \%$ & 9 & $47.40 \%$ & & \\
\hline \multirow[t]{2}{*}{ Hypertension } & No & 85 & 38 & $73.10 \%$ & 34 & $85.00 \%$ & 13 & $68.40 \%$ & 2.642 & 0.267 \\
\hline & Yes & 26 & 14 & $26.90 \%$ & 6 & $15.00 \%$ & 6 & $31.60 \%$ & & \\
\hline \multirow[t]{2}{*}{ Anatomy } & No & 28 & 12 & $23.10 \%$ & 12 & $30.00 \%$ & 4 & $21.10 \%$ & 0.786 & 0.675 \\
\hline & Yes & 83 & 40 & $76.90 \%$ & 28 & $70.00 \%$ & 15 & $78.90 \%$ & & \\
\hline
\end{tabular}




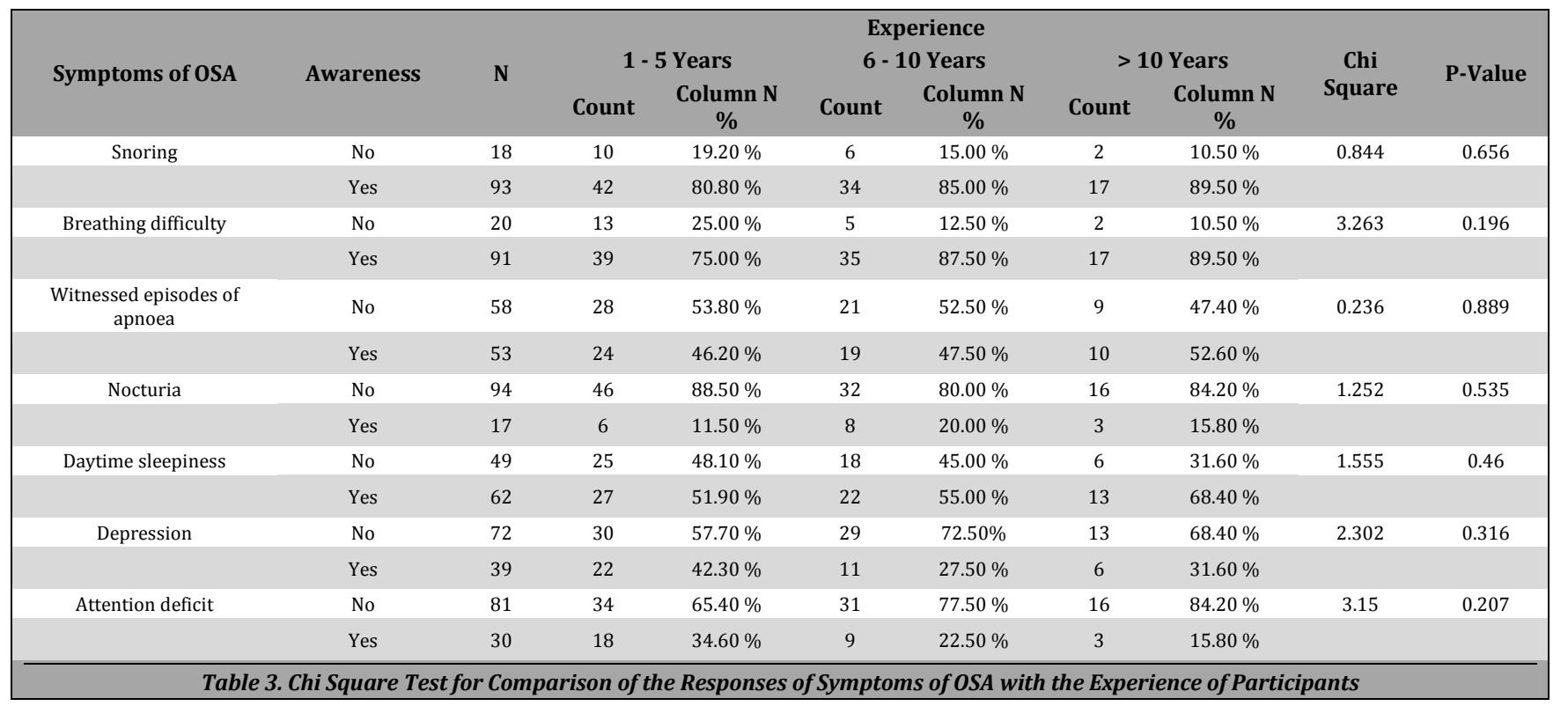

\begin{tabular}{|c|c|c|c|c|c|c|c|c|c|c|}
\hline \multirow{2}{*}{ Treatment of OSA } & \multirow{2}{*}{$\begin{array}{c}\text { Awarenes } \\
\text { s }\end{array}$} & \multirow{2}{*}{$\mathbf{N}$} & \multicolumn{4}{|c|}{$\begin{array}{l}\text { Experience } \\
6 \text { - } 10 \text { Years }\end{array}$} & \multicolumn{2}{|c|}{$>10$ Years } & \multirow{2}{*}{$\begin{array}{c}\text { Chi } \\
\text { Square }\end{array}$} & \multirow{2}{*}{$\begin{array}{c}\text { P- } \\
\text { Value }\end{array}$} \\
\hline & & & Count & $\underset{\%}{\text { Column N }}$ & Count & $\underset{\%}{\text { Column } N}$ & Count & $\underset{\%}{\text { Column } N}$ & & \\
\hline \multirow[t]{2}{*}{ Lifestyle changes } & No & 34 & 17 & $32.70 \%$ & 12 & $30.00 \%$ & 5 & $26.30 \%$ & 0.278 & 0.87 \\
\hline & Yes & 77 & 35 & $67.30 \%$ & 28 & $70.00 \%$ & 14 & $73.70 \%$ & & \\
\hline \multirow[t]{2}{*}{ Alcohol restriction } & No & 73 & 34 & $65.40 \%$ & 29 & $72.50 \%$ & 10 & $52.60 \%$ & 2.265 & 0.322 \\
\hline & Yes & 38 & 18 & $34.60 \%$ & 11 & $27.50 \%$ & 9 & $47.40 \%$ & & \\
\hline \multirow[t]{2}{*}{ CPAP } & No & 54 & 26 & $50.00 \%$ & 18 & $45.00 \%$ & 10 & $52.60 \%$ & 0.372 & 0.83 \\
\hline & Yes & 57 & 26 & $50.00 \%$ & 22 & $55.00 \%$ & 9 & $47.40 \%$ & & \\
\hline \multirow[t]{2}{*}{ Intraoral appliances } & No & 31 & 14 & $26.90 \%$ & 13 & $32.50 \%$ & 4 & $21.10 \%$ & 0.888 & 0.642 \\
\hline & Yes & 80 & 38 & $73.10 \%$ & 27 & $67.50 \%$ & 15 & $78.90 \%$ & & \\
\hline \multirow[t]{2}{*}{ Surgery } & No & 51 & 29 & $55.80 \%$ & 16 & $40.00 \%$ & 6 & $31.60 \%$ & 4.169 & 0.124 \\
\hline & Yes & 60 & 23 & $44.20 \%$ & 24 & $60.00 \%$ & 13 & $68.40 \%$ & & \\
\hline \multirow[t]{2}{*}{$\begin{array}{c}\text { Polysomnography-gold std } \\
\text { diagnosis }\end{array}$} & No & 50 & 25 & $48.10 \%$ & 19 & $47.50 \%$ & 6 & $31.60 \%$ & 1.682 & 0.431 \\
\hline & Yes & 61 & 27 & $51.90 \%$ & 21 & $52.50 \%$ & 13 & $68.40 \%$ & & \\
\hline
\end{tabular}

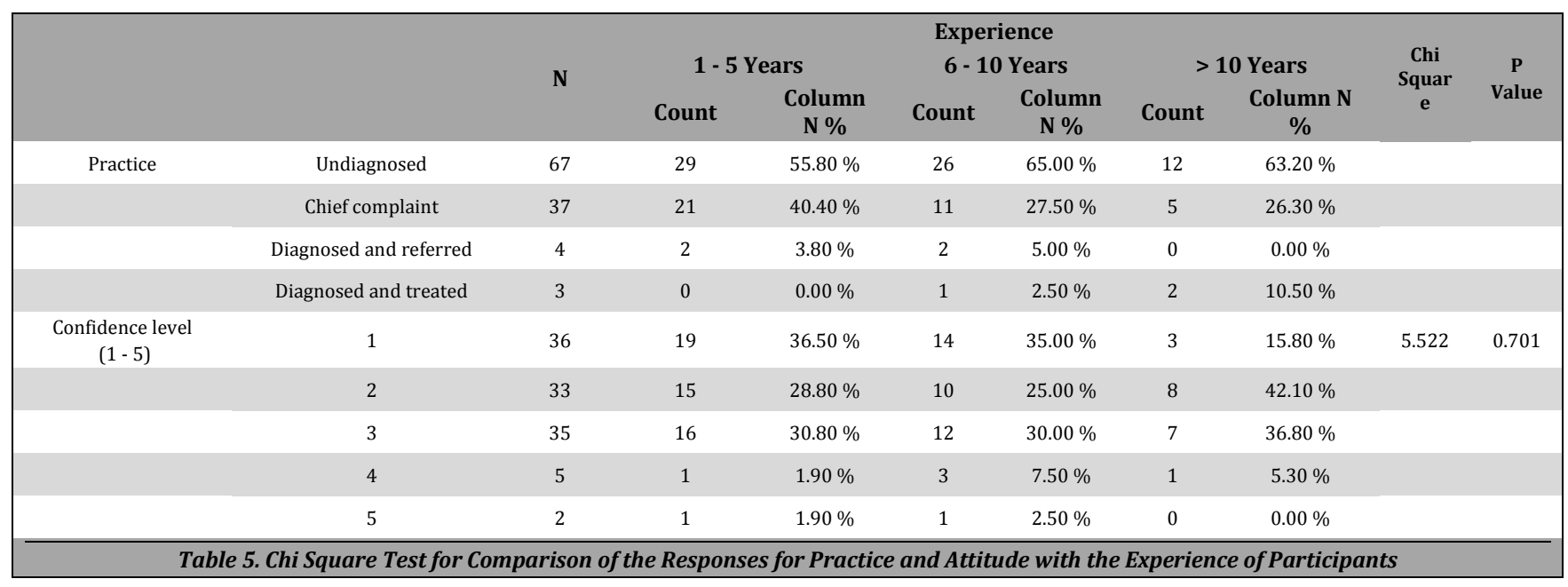

The years of experience of the dental clinician was categorized into three groups of 1 - 5 years of experience (47 $\%), 6$ - 10 years of experience (36\%) and more than 10 years of experience (17\%). The tables $1-4$ describe the years of experience in comparison with response

Response such as awareness of CVS as complication was $62.50 \%$ among 6 - 10 years of experience, $40.40 \%$ among 1 5 years of experience and $26.30 \%$ among $>10$ years of experience and these results were statistically significant with the P-value of (0.018). Response to awareness of age being a predisposing factor was $92.50 \%$ among 6 - 10 years experienced dental clinicians, $65.40 \%$ among 1 - 5 years experienced dental clinicians and $78.90 \%$ among $>10$ years of experience and these results were statistically significant with the P-value of (0.008). Response to awareness of snoring as a predisposing factor was $52.50 \%$ among 6 - 10 years 
experienced, $28.80 \%$ among 1 - 5 years experienced and 15.80 $\%$ among $>10$ years of experience and these results were statistically significant with the P-value of $(0.009)$

The other responses were statistically non-significant when analysed in comparison with years of experience. Table 5 describes the practice and attitude of the participants in comparison with the years of experience. The statistics showed no clinical significance.

\section{DISCUSSION}

Obstructive sleep apnoea is a condition in the upper airway tract, where the size of the pharyngeal airway lumen is constricted due to either craniofacial structure or increased body fat, leading to pharyngeal collapse. Other contributing factors are sex, age, increased neck circumference of $43 \mathrm{cms}$ or 17 inches, snoring, hypertension etc.2,11,12

An obese male has a major risk factor for obstructive sleep apnoea. ${ }^{14}$ The anatomy of the upper airway tract of men predisposes them to pharyngeal collapse more than women. Age also plays a major role as a risk factor since the efficiency of the dilator muscles of the upper airway decreases with age. ${ }^{15}$

Obstructive sleep apnoea is associated with a host of medical consequences that virtually affect every major organ system. The symptoms include snoring, restless sleep, nocturnal enuresis, daytime sleepiness, irritability, lack of concentration, reduced alertness, memory loss and depression. Other consequences are reduced vigilance, increased errors, impaired work efficiency, increased risk for accidents and decreased quality of life. Daytime sleepiness is one of the most common complaint of sleep apnoea, along with lack of energy, tiredness and fatigue. ${ }^{7}$

A polysomnography reading is considered to be the "gold standard" for the diagnosis of sleep disorders. Physiological changes occur in various organ systems that are influenced by sleep and wakefulness. A polysomnography records the physiological function of these organ systems and the qualitative and quantitative abnormalities of sleep and wakefulness and the sleep-wake transition. ${ }^{16}$

The treatment of sleep apnoea depends on its severity. Asymptomatic patients or patients whose symptoms are not bothersome and pose no risk to vehicular accidents, can be treated with behavioural measures. ${ }^{17}$ Behavioural modifications include exercise, weight loss, positional therapy and restriction of alcohol consumption \& sedative medications before bedtime.18 For patients with excessive sleepiness and resistant hypertension, a positive airway pressure therapy is recommended. ${ }^{17}$ Continuous positive airway pressure (CPAP), is considered the gold standard treatment for OSA. The n-CPAP is administered through the nose and is recommended as the first choice of treatment for patients with moderate to severe OSA. An alternative treatment to CPAP is oral appliances such as mandibular advanced devices (MAD). These devices attach to both maxillary and mandibular arches and advance the mandible in a forward position. This moves the tongue base forward and relocates the pharyngeal fat pads laterally and widens the airway. For patients with severe apnoea and where treatment with CPAP has failed, an uvulopalatopharyngoplasty procedure can be considered. ${ }^{19}$

\section{CONCLUSIONS}

The descriptive data suggests that the dental clinicians included in this survey were relatively under informed about the severity of the disorders and its medical and social ramifications. The knowledge scores when compared with the years of experience showed that there was statistical significance regarding knowledge of cardiovascular disease as a complication of OSA with age and snoring as predisposing factors for OSA. The chi-square test indicated that the experience group of 6 - 10 years had better knowledge than the other groups of 1 - 5 years and > 10 years. There was no statistical significance in comparison with the other knowledge factors when compared to the years of experience; this could be suggestive of lack of awareness of OSA in the dental curriculum as well as lack of resources such as continued dental education and seminars for updating the knowledge on OSA for practicing dentists. There is an urgent need to create awareness among dental students and clinicians regarding OSA and its association as a risk factor for stroke and hypertension. This awareness can increase the diagnosis, prevention and treatment of OSA and the morbidity and mortality associated with it. A dedicated training about sleep disorders should be included in the dental curriculum for both undergraduate and post graduate students.

Data sharing statement provided by the authors is available with the full text of this article at jemds.com.

Financial or other competing interests: None.

Disclosure forms provided by the authors are available with the full text of this article at jemds.com.

\section{REFERENCES}

[1] Sia CH, Hong Y, Tan LWL, et al. Awareness and knowledge of obstructive sleep apnea among the general population. Sleep Med 2017;36:10-7.

[2] Jordan AS, McSharry DG, Malhotra A. Adult obstructive sleep apnoea. Lancet 2014;383(9918):736-47.

[3] Papp KK, Penrod CE, Strohl KP. Knowledge and attitudes of primary care physicians toward sleep and sleep disorders. Sleep Breath 2002;6(3):103-9.

[4] Reuveni H, Tarasiuk A, Wainstock T, et al. Awareness level of obstructive sleep apnea syndrome during routine unstructured interviews of a standardized patient by primary care physicians. Sleep 2004;27(8):1518-25.

[5] Schotland HM, Jeffe DB. Development of the obstructive sleep apnea knowledge and attitudes (OSAKA) questionnaire. Sleep Med 2003;4(5):443-50.

[6] Corso RM, Sorbello M, Buccioli M, et al. Survey of knowledge and attitudes about obstructive sleep apnoea knowledge among Italian anaesthetists. Turk J Anaesthesiol Reanim 2017;45(3):146-52.

[7] Gurubhagavatula I. Consequences obstructive sleep apnoea. Indian J Med Res 2010;31:188-95.

[8] Samaranayake CB, Arroll B, Fernando AT. Sleep disorders, depression, anxiety and satisfaction with life among young adults: a survey of university students in Auckland, New Zealand. N Z Med J 2014;127(1399):13-22.

[9] Ficker JH, Dertinger SH, Siegfried W, et al. Obstructive sleep apnoea and diabetes mellitus: the role of cardiovascular autonomic neuropathy. Eur Respir J 1998;11(1):14-9. 
[10] Parish JM, Somers VK. Obstructive sleep apnea and cardiovascular disease. Mayo Clin Proc 2004;79(8):103646.

[11] Stradling JR, Crosby JH. Predictors and prevalence of obstructive sleep apnoea and snoring in 1001 middle aged men. Thorax 1991;46(2):85-90.

[12] Kamil MA, Teng CL, Hassan SA. Snoring and breathing pauses during sleep in the Malaysian population. Respirology 2007;12(3):375-80.

[13] Desalu O, Onyedum C, Sanya E, et al. Prevalence, awareness and reporting of symptoms of obstructive sleep apnoea among hospitalized adult patients in Nigeria: a multicenter study. Ethiop J Health Sci 2016;26(4):321-30.

[14] Patil S, Schneider H, Gladmon E, et al. Obesity and upper airway mechanical control during sleep. Am J Respir Crit Care Med 2004;169:A435.
[15] Malhotra A, Huang Y, Fogel R, et al. Aging influences on pharyngeal anatomy and physiology: the predisposition to pharyngeal collapse. Am J Med 2006;119(1):e9-14.

[16] Kakkar RK, Hill GK. Interpretation of the adult polysomnogram. Otolaryngol Clin North Am 2007;40(4):713-43.

[17] Gottlieb DJ, Punjabi NM. Diagnosis and management of obstructive sleep apnea: a review. JAMA 2020;323(14):1389-1400.

[18] Epstein LJ, Kristo D, Strollo PJ, et al. Clinical guideline for the evaluation, management and long-term care of obstructive sleep apnea in adults. J Clin Sleep Med 2009;5(3):263-76.

[19] Spicuzza L, Caruso D, Maria GD. Obstructive sleep apnoea syndrome and its management. Ther Adv Chronic Dis 2015;6(5):273-85. 